group of famous memoirs on the rationality of plane involutions, the conditions of rationality of a surface, and an exhaustive study of linear systems of curves on a surface, with all the remarkable inferences which can be drawn from it. So intense was this period of research that few fundamental questions remained to be settled afterwards. One of them, however, was disposed of only a year ago, by Beniamino Segre.

In the ensuing period the author's interest turns from the methods of algebraic geometry proper to the consideration of transcendental questions. The most celebrated paper of this group contains the theorem that the number of simple, everywhere finite integrals attached to an algebraic surface is equal to the so-called irregularity of the surface.
This third series concludes with some interesting researches on Abelian functions. The final paper is devoted to a very different topic-the statistical problem of moments.

To anyone with a knowledge of Italian, though not necessarily of geometry, these papers will have an extra-mathematical interest : they are written in a style which for sheer lucidity and directness has never been surpassed. Castelnuovo has that rare capacity for going straight to the heart of a difficult problem, of seeing where the difficulty lies, and resolving it in successive stages, all apparently of the utmost simplicity. Altogether, this book is the most fitting memorial to the great period of Italian mathematics which now, it seems, is drawing to a close.

\title{
Laboratory Experiments in Biochemistry
}

Fundamentals of Biochemistry, with Laboratory Experiments

By Prof. Carl L. A. Schmidt and Dr. Frank Worthington Allen. (International Chemical Series.) Pp. xv +388. (New York and London: McGraw-Hill Book Co. Inc., 1938.) 18s.

THIS is a book for the beginner in America. It starts with a definition of the purpose of laboratory training which every old stager in science will applaud. "The incalculable gift of the laboratory is its discipline in scientific method and its training in the importance of logical reasoning and the use of exact language in speaking and in writing." The student is enjoined to supply himself with a laboratory coat, a box of matches, a set of weights, a note-book and a slide rule. So equipped, the scientific world lies open before him.

The standard of biochemistry and chemical physiology is so high in the United States to-day that one may justly infer that the subject is being well taught, particularly in the laboratory. The object of the special experiments here described is defined as "to teach the student the sources of the facts of biochemistry, to integrate information, to carry out a well-controlled experiment and to present the facts in a co-ordinated and logical manner".

There is no doubt that the object is the same in Great Britain also, but any time when half a dozen employers are gathered together, they will tell you that the normal product of the British university definitely fails to meet such criteria. The question may justifiably be asked whether our present training is not too theoretical ? As has been aptly written by Dr. S. Miall, "We should not regard the young as carboys into which you can put pints or litres of knowledge". For the moment the fight against examinations as the one test of education appears lost or in abeyance; there are but few reformers left to combat in this field. The fact remains, however, that in many respects the Americans are better trained, more practical to-day than British graduates; it is evidenced by the way the United States is going ahead in scientific work and, what is more important, in its practical application.

It is opportune to sound this warning note, and to express the hope that teachers in Great Britain will examine with care books such as this one, so that they may ascertain the difference between British and American methods.

This is not the place for its detailed examination ; there is no novelty in the experiments or in the facts presented in its text, which is crisp and contains a great deal of information in a small compass. Its perusal leaves us with the feeling, rightly or wrongly, that it would inspire a young man to dig further into the subject and try to keep abreast of its progress. The essential facts are clearly presented whether the substance is simple or complex in structure.

$$
\begin{aligned}
& \text { "Further, deeper may you read, } \\
& \text { Have you sight for things afield," }
\end{aligned}
$$

says Meredith. Surely it is in this spirit that the training of men whose work takes them near to Nature should be conducted.

E. F. A. 